\title{
HIVIAIDS Awareness Campaign through Sports in Yangon: The Pioneering Service-Learning Program of Dagon University, Myanmar
}

\author{
Aye Aye Tun ${ }^{1, *}$ and Allen V. Del Carmen ${ }^{2}$ \\ ${ }^{1}$ Dagon University, Min-Ye-Kyaw-Swar Road, Ward No. 133, Dagon Myothit (East), \\ Yangon, Myanmar \\ ${ }^{2}$ Communication Department, University of St. La Salle, La Salle Avenue, Bacolod \\ 6100,Negros Occidental, Philippines
}

\begin{abstract}
Rapid sports programs and activities have served as an avenue to unify people of diverse backgrounds and persuasions. More than promoting national or local pride and contributing to friendship, sportsmanship and social unity, sports also serves as a tool to popularize certain advocacies. Dagon University in Myanmar took advantage of this value of sports when it implemented "Playing Football, Learning HIV AIDS", "A Football for Development" program, a pioneering ServiceLearning Program focused on utilizing football training activities as a tool for social action through HIV/AIDS information and education campaign for school children in 2015. In a country where about 220000 people are living with HIV/AIDS, including 77000 women, sports can be used for social action to increase awareness. This paper looks into the pioneering effort of the university and how sport for social action can be expanded to further promote peace and development.
\end{abstract}

Keywords: HIV/AIDS awareness, sports in service learning, Yangon

\section{Introduction}

To the turn of the century has ushered in a reinvigorated dimension in sports as a potential tool for social development. Various initiatives were launched to widen its appeal not only to showcase domination and competitive excellence and also as a tool for physical fitness and entertainment, but also as an avenue for the development of people and communities. This new dimension is realized in the utilization of sports as a tool to promote social change. Global organizations like the Homeless World Cup, founded in South Africa and the Street Basketball Association in the United States were formed in 2001 to provide the homeless and inner city youth an opportunity for them to be inspired to change their lives through football and basketball. The end-goals are for the youth to build character, confidence, responsibility, accountability and other qualities toward individual, family and community development [1].

${ }^{*}$ Corresponding author: ayeayetun1961@gmail.com 
In March 2016, the World Street Child Games was held in Rio de Janiero in Brazil, "reminding the world of sport's unique power to bring people together to promote social change" [2]. The games included a Congress, where the participants developed the Rio Resolution, which calls on the world to take concrete steps to protect street children's universal rights from violence and toward access to education and legal identity.

\section{Sports-focused service-learning}

Joining the bandwagon are academic institutions, particularly those with Sports Management and allied programs. This development dwells well with the Functional Theory, one of the six propositions in "Sports in Society-Issues and Controversies", theories used to study sports in society. Functional Theory expounds that sports are studied in terms of their contribution to the society with researches focusing on positive outcomes [3].

The positive effects and benefits of sports have been "chronicled in the professional academic literature" [4]. Mumford and Kane also stated that participation in athletics have increased the promotion of health and prevention of disease along with benefits in other aspects. Bringle and Hatcher (as cited by Miller and Nendel [5]) also noted that universities have shown interest in giving their resources to develop citizenship among their students, using service learning as a "pedagogical tool" in many disciplines, among which is physical education.

Many universities in the United States have initiated sports for social action program, particularly under their Service-Learning program. Among those that looked into the value of sports-oriented Service-Learning activities were Kimberly A. Bush, Michael B. Edwards and Gareth J. Jones of North Carolina State University along with Jessica L. Hook and Michael Armstrong. The team explored the use of sports to leverage for social change [6]. The researchers covered the Hoops against Hunger project that provided relief to victims of Florida hurricanes. Proponents, like Bush and others, have underscored that an S-L sports activity "demonstrated its ability to serve as a mechanism for social changes."

\subsection{Sport for development and peace}

Giving more substance to these initiatives is the recent celebration of the International Day of Sport for Development and Peace held on April 6. The celebration has been mandated since the U.N. General Assembly adopted Resolution 67/296 on August 23, 2013. The UN recognizes sports for the values they nurture and support, like fairness, mutual respect and teamwork which promote a life of peace through solidarity [7]. The sport for development model as pointed out in the Bush study has served as an agent to address the issues of poverty, education accessibility, barriers to social mobility and health issues.

The thrust has continued to gain roots far and wide. Many studies have addressed the relationship between HIV/AIDS and sports [8]. In Nigeria, based on Sport and Development in 2013, its use has been adopted as a tool for HIV/AIDS prevention. Young girls are educated about HIV and its prevention as well as gender equality. There are also Non-Government Organizations in South Africa where they use sports as a strategy to respond to HIV/AIDS, however, according to [9], there are only few reports regarding the outcomes of the programs.

\subsection{Asia-Pacific and Southeast Asia service-learning}


In the Asia-Pacific region, universities have followed suit. At the University of Victoria in Melbourne, Australia, a service-learning case study has been made on its benefits at its School of Sports and Exercise Science. At the Hong Kong Polytechnic University, Prof. Brian E. M. King conducted a study to strengthen funding for community sports program that benefits service-learning activities of students. Lingnan University has an intergenerational recreational service-learning program that has been going on for years. In 2015, a group of Physical Education majors conducted sports clinics at the International Service-Learning engagement in an island in the Philippines as a post-trauma intervention for children who suffered from a devastating typhoon.

The seed has been sown also in the Southeast Asian region. It appears, however, that activities and documentation remain few. Communication students of the University of St. La Salle in the Philippines included, in a multi-phased Service-Learning activity, a beach football and beach volleyball program for island-children to promote physical fitness in an while veering them away from the possible vices that lure the youth [10].

\section{The Myanmar situation}

In 2015, Dagon University in Myanmar, Yangon conducted an S-L activity, particularly to raise awareness on HIV/AIDS, a pandemic health phenomenon that has claimed the lives of $1.1 \times 10^{6}$ people in the world, including about 130000 in Southeast Asia [11]. In Myanmar, the number of people living with HIV/AIDS (among $15 \mathrm{yr}$ old and above) has increased to 200000 in 2015 from 190000 in 2013 [12, 13].

Dr. Tun Aung Shwe, a Myanmar native who is with the University of New South Walers' School of Public Health and Community Medicine, said that as early as 2002, HIV/AIDS cases in Myanmar were already significantly high as it had the second highest infection rate in the region [14]. Dr. Tun Aung Shwe has initiated a Sports for Social Action program in his home country and inspired the Dagon S-L pioneering project. The UNAIDS report also indicated that another 77000 women aged $15 \mathrm{yr}$ old and above and 9500 children aged $14 \mathrm{yr}$ and below are also living with HIV/AIDS. The records further showed that the death toll was reached 9400 with 110000 children aged until $17 \mathrm{yr}$ orphaned due to HIV/AIDS.

Myanmar is one of the five countries which FIFA, the global football governing body, identified for the implementation of the 'Protect the Goal' campaign, an innovative partnership among UNAIDS, the Asian Football Confederation and the Asian Development Bank is promoting for a football-based HIV prevention program in the region. The Myanmar implementation is being undertaken with the support of the Myanmar National Football League and Football United, which is a flagship program of the UNSW [12]. Dr. Shwe introduced the idea to sports for social action to Dagon.

\section{Dagon and its S-L program}

The growing number of HIV/AIDS incidence in Myanmar has posed a challenge for sectors to help address the escalating health concern. Among these sectors is Dagon University, a state-owned and operated university located in North Dagon in the outskirts of Yangon, Myanmar. It was founded in 1993 and has a population of about 60000 regular and distance-learning students.

In December 2013, the university forged an agreement with the United Board for Christian Higher Education in Asia for the implementation of service-learning. Since its introduction, university officials and faculty were given a series of exposures and trainings on curriculum planning and program implementation conducted by visiting lecturers from 
two Philippine educational institutions - Silliman University and University of St. La Salle. The trainings provided faculty members with skills in developing course content and preparations for the actual implementation and evaluation. Target students for the program also participated in the training.

\subsection{The pioneering program in Myanmar}

The first-ever service-learning program conducted in a Myanmar university took place in 2015 as an offshoot of earlier trainings. The pioneering Dagon S-L activity was inspired by the July 2014 visit of Dr. Tun Aung Shwe, UNSW assistant director of Football United and also of the Football United Myanmar. Dr. Tun Aung Shwe conducted a capacity building training entitled, "service-learning in Dagon University, a Football-based Youth and Community Development Project". The training, attended by students of the Football Coaching class, aimed to build capacities of students and teachers who would participate in the planned sports science S-L project, "Playing Football, Learning HIV AIDS", a sport clinic anchored on the ideals of social action and development.

\subsection{Objectives}

The training objectives were five-pronged: The application of students' knowledge in coordinating, organizing, implementing and coordinating a football event; sharing of their knowledge on the value of good health in sports in the context of "a sound body and a sound mind"; sharing of their expertise on the sport of football and the value of individual skills and ability in relation to team performance; conducting an evaluation of their activity, analyzing their data and making an accomplishment report; and writing and sharing their learning insights with other students. The June training particularly helped the studentparticipants identify tasks to be done and organized them by functions. Overall leaders created a Facebook account (SL and FFD), which carried photos and testimonials of participants.

\subsection{The implementation}

The service-learning project of the football coaching class was eventually conducted for four Saturdays in July and August 2015, following two separate additional training programs conducted by the authors to further prepare the university in the implementation of the sports-based social action S-L project, which had three resource persons-Dr. Tun Aung Shwe and the authors of this paper, Dr. Aye Aye Tun, who was then Vice-Rector for Academic Affairs and presently Pro-rector, and Prof. Allen Del Carmen, visiting lecturer from the University of St. La Salle in the Philippines who followed up Silliman Prof. Emervencia Ligutom's workshops Dr. Tun Aung Shwe prepared the guide outline used by Dagon students in the HIV/AIDS lessons for the participating schoolchildren. Supervising the activity with the author, Dr. Aye Aye Tun, were three university faculty-Dr. Soe Ni Tun of the Department of Archaeology, Dr. Wathin Chit of the Department of Geology and Daw Kyi Kyi Win of the Department of Oriental Studies.

\subsubsection{University participants}

A total of 23 students - 21 Sports Science majors and two others from other departments who have undergone specialized coaching studies - participated in the project. Total seven of the Dagon University students were females. The activity was held on the Dagon 
University football grounds for $5 \mathrm{~h}$ every session with students earning a maximum of 20 service hours in the sessions held on July 18, July 25, August 1 and August 8.

\subsubsection{Children participants}

The total of 48 school children were recruited by the Dagon students themselves from four neighboring schools-Byong-tine Monastic School, BEHS No. 2, BEPS No. 6, and BEPS No. 6. Almost 34 (35 of 48 pupils) were in Grades 7, 8 and 9, with 11 were both fifth or sixth graders and one each belonging to the first and third grades. Total of Five children $(10.4 \%)$ were girls, the low number reflecting the traditionalist orientation of Myanmar families that football is a sport for males.

\subsubsection{The sessions}

The first session allotted time for the discussion about HIV/AIDS-its nature, causes, prevention and related facts. It was followed by the football clinic, which covered all technical aspects of playing the game, including rules, dynamics regulations, equipment and the value of fair play.

\section{Evaluation and findings}

A multi-phased evaluation was conducted. One set was accomplished by the schoolchildren and the other by the S-L student. The evaluation done by the students included accomplishment of questionnaires, reflection through sharing and journal writing.

\subsection{Children's mood meter}

A mood meter was used to determine children's interest in the activity. Almost all children answered that they were very happy to attend the course. The meter assessment was done every session showing identical results. The S-L activity took advantage of the fact that children, regardless of sex and status, love to play, particularly with their peers regardless of status, age and other factors. Their common "very happy" response indicates that love for play and fun activities.

\subsection{Knowledge of HIV and AIDS}

Children were asked to answer 19 questions in pre-test and post-test sessions reflecting their knowledge of HIV-AIDS. The table below reveals that the children's knowledge had been enhanced at the end of this program.

Table 1. Pre-test and post-test results

\begin{tabular}{|l|c|c|c|c|c|}
\hline $\begin{array}{c}\text { Correct } \\
\text { Answer }\end{array}$ & $\mathbf{0 ~ t o ~ 5}$ & $\mathbf{6}$ to 10 & $\mathbf{1 1}$ to 15 & $\mathbf{1 6}$ to 19 & Total \\
\hline Before & $\begin{array}{c}12 \\
(26.67 \%)\end{array}$ & $\begin{array}{c}8 \\
(17.78 \%)\end{array}$ & $\begin{array}{c}21 \\
(46.67 \%)\end{array}$ & $\begin{array}{c}4 \\
(8.89 \%)\end{array}$ & 45 \\
\hline After & $\begin{array}{c}0 \\
(0 \%)\end{array}$ & $\begin{array}{c}2 \\
(4.65 \%)\end{array}$ & $\begin{array}{c}5 \\
(11.63 \%)\end{array}$ & $\begin{array}{c}36 \\
(83.72 \%)\end{array}$ & 43 \\
\hline
\end{tabular}


As reflected in the table above, learning was significant. While 12 participants answered correctly only five questions or less, the post-test result showed no one no longer scored that poorly. A similar pattern occurred in the six to 10 correct answers, which is down from eight to two in the post-test. A number of 21 scored 11 to 15 in the pre-test with the post-test outcome totaling only five, which can be explained by the rise in 16 to 19 correct answers. The increase in the frequency of 16 to 19 correct answers-from only four in the pre-test to 36 of the 43 who took the post test-registers $83.72 \%$.

\subsection{Children's training appreciation and feedback}

At the end of the program, children were also asked to rate their appreciation of the activity using a five-point scale: 1 boring, 2 not interested, 3 average, 4 happy and 5 very happy. A number of 39 children $(81.25 \%)$ answered they were "very happy". In addition, 29 children $(60.4 \%)$ requested Dagon to either extend the activity or hold a similar project in near future. Two children wrote that they need football shoes, while another suggested that activities should have also been included to make the children be acquainted more with each other to enhance team spirit while learning.

A number of children expressed their deepest gratitude to Dagon University as they said they gained a lot of knowledge and techniques not only in their football skills but also in their HIV/AIDS awareness. While the activity was conducted during rainy days, interest and enthusiasm, of majority of the children were high as an average of $60 \%$ in the attendance was noted despite the bad weather and the distance from the homes of some of the participants. Because of the differences in task assignments, attendance of university students varied by session with majority of them present on the final session. Some absences were noted due to conflicts in weekend schedule, illnesses and low motivation.

\section{Dagon students' evaluation}

Two general pen-and-paper evaluations were accomplished by the students: one on the aspects of the conduct of the training and the other on the students' perceptions of the extent of their learning from the community service activity. Both used a five-point scale with No. 1 as the lowest and No. 5 as the highest.

Table 2. Student's perception of training aspects.

\begin{tabular}{|l|l|}
\hline Training Aspects & $\begin{array}{l}\text { Students' Rating using } \\
\text { Scale of 5 }\end{array}$ \\
\hline Training objectives defined & 4.56 \\
\hline Training objectives attained & 4.17 \\
\hline Scheduling & 4.30 \\
\hline Training Venue & 4.04 \\
\hline Training Materials & 3.60 \\
\hline Resource Persons & 4.04 \\
\hline Training Staff & 3.48 \\
\hline Training Equipment & 2.69 \\
\hline My Own Learning & 4.13 \\
\hline My Classmates' Learning & 4.04 \\
\hline Overall Rating & 4.78 \\
\hline Average & $\mathbf{3 . 9 0}$ \\
\hline
\end{tabular}

The results show that while the average of the nine aspects of the training was a little lower than 'high' (3.90), the university students gave a high mark on their overall rating 
(4.78) with the definition of training objectives ranking second (4.56) and schedule (4.30), third. Assessment was 'high' in other aspects except in three parts - training materials (3.60), the training staff (3.48) and the lowest the availability of equipment (2.69). The rating of the training staff, which is a little lower than "good" is apparently based on the fact that only students facilitated the skills aspects of the training. The poor assessment of equipment also surfaced in the students' comments and journal.

\subsection{Butin evaluation model and results}

The other evaluation is based on the four-dimension model of Dan Butin (Oracion) which is designed to measure the extent and significance of the students' learning using four factors: technical learning, political learning, cultural learning and anti-foundational learning. Specific areas were considered based on the coverage of each learning mode. The Butin formula measures technical learning and application (knowledge and skills relevant to the topic), cultural learning (absorption of the ways of the participants who come from various backgrounds), political (in relation to organizational practices and structures) and anti-foundational learning, which challenge students to look at things from an entirely different point of view. The assessment revealed a 'high' average despite the antifoundational rating (3.83), which is between 'average' and 'high'. The anti-foundational rating is understandable given the orientation and nature of most students, who are used to lean on tested-and-proven ways.

Table 3. Students' level of learning based on Butin's model.

\begin{tabular}{|l|l|}
\hline Butin Learning Models & Students' rating \\
\hline $\begin{array}{l}\text { Technical Knowledge } \\
\text { (About application/sharing of course-related skills, knowledge } \\
\text { and values with the schoolchildren and report preparation) }\end{array}$ & 4.20 \\
\hline $\begin{array}{l}\text { Political 4.30 } \\
\text { (About coordination with communities and leaders } \\
\text { *Based on a cross-checking question as students wrote no } \\
\text { answer, apparently equating political learning with the issue of } \\
\text { politics and affiliation, then a sensitive concern) }\end{array}$ & 4.30 \\
\hline $\begin{array}{l}\text { Cultural } \\
\text { (About participants' ways, habits and attitudes) } \\
\text { (Extent of learning about participants and their ways) }\end{array}$ & 4.34 \\
\hline $\begin{array}{l}\text { Anti-foundational } \\
\text { (Development of knowledge, ideas and practices different from } \\
\text { usual ways) }\end{array}$ & 3.83 \\
\hline Average & $\mathbf{4 . 1 5}$ \\
\hline
\end{tabular}

Getting the highest rating is cultural learning (4.30). This is consistent with the students' observations and comments about being able to understand the children, many of whom come from a background different from, theirs. Another possible explanation for the high rating is that students were given the opportunity as a class to be exposed to community life and activities for the first time.

In the evaluation sheet, the students left the political learning blank, despite the explanation of the coverage of this element, perhaps because they equate the term with something about governance, which measures their effective in coordination and observing protocol, procedures and system. The rating for this aspect was culled from a crosschecking question on organization and coordination. With the political perspective excluded from the result, the average in the three learning insights is 4.15 , slightly lower than the 4.17 if the political assessment is included 


\subsection{Reflection}

Another evaluation tool was used - this time as an open-ended reflection guide in a group discussion. The following is the summary of their responses:

(i). All university students agreed in the need to sustain or continue the training activity.

(ii). Both service providers and receivers were very happy to participate; gained knowledge on football coaching (deeper understanding of subject matter) and on HIV/AIDS (health education)

(iii). Increased learning and motivation

(iv). Ability to apply course material in real situation

(v). Opportunity to learn from the peers

(vi). It also enhanced the students' soft skills, like leadership, coordination and collaboration

A few students complied with the journal requirement, which gives details of the dayto-day insights of the student.).

\subsection{Journals}

The following were among the university students' impressions taken from the third phase of the evaluation the journals.

(i). "As it was the first experience for me, I was very excited before the event."

(ii). "Strategic planning before the event is very important. I used the lesson, 'Coaching Football' that I have learned in my academic subjects."

(iii). "The rain affected the activities. We needed more teaching and training materials, like balls, colored cone, etc. However, I am glad, however, that I overcame the problems."

(iv). "The experience I have gained from this S-L activity has reinforced my learning in academic subjects. In addition, I have confidence, feel more mature and ready for my future career."

(v). "Challenges: Low physical fitness of children; they were more interested in playing than in health "education."

(vi). "Difficulty: Not enough teaching aids."

(vii). "What made me happy: I was able to share football techniques and health education; I gained new knowledge on football coaching, developed close attachment with the children; I saw that the children were very happy and pleased to join this event; children listened the words of teachers."

(viii). "I realized that I can do something for these children and hope to do more for my communities.").

\subsection{Suggestions}

A sense of program ownership was evident as students articulated suggestions to ensure better implementation in the future. They suggested that:

(i). It is better to conduct the activity during holidays or summer.

(ii). They revealed their satisfaction after exhausting all efforts to conduct the activity, knowing they have realized their goals.

(iii). They expressed the need for enough equipment. Including balls, cones, markers, bibs, shoes and others. 
(iv). Another suggestion was for the establishment of a "Sport for Community Development Center" in the university which will be useful for sports-focused Service-Learning activities.

(v). The program must be expanded to include distant communities which are not reached by social action activity and where the need is highly felt.

(vi). It was recommended that the Sports Science Service-Learning program will include other disciplines or sports for the development of lifetime skills.

\subsection{Follow-up activities}

As a follow up, another S-L training was done in August 2016, this time focusing on health and sports leadership skills. In January and February 2017, 50 university students from different disciplines were trained on coaching with students - who were later groupedconducting their own sports training in five communities.

\section{Conclusion}

For a long time, university life in Myanmar had been focused mainly on the education of the mind, considering the long socio-political situation in the country. Consequently, distance learning became popular. Structured community service and engagement was hardly a part of the curricular content. With universities expanding their vision and mission in the past years, the idea of serving communities was readily embraced by the schools and students, who saw an occasion for using their knowledge and skills gained in the classroom for sharing, especially in promoting not only sports skills, but also and more significantly, in increasing awareness among young people on a health concern, like HIV-AIDS. The students' comments, evaluation and journals are testimonials to their realization that they can use their knowledge and skills through social action that promotes citizenship building and civic pride by helping mold the younger generation. Their appreciation of their pioneering S-L experience spurred them to continue and expand the program to cover more social concerns.

The pioneering program had its share of shortcomings - from equipment and materials to time constraints and inconsistent participation by some students and children, but what the team leader said summarizes the impact of the Service Learning experience among Dagon Sports Science students: "I am glad I was part of the first-ever S-L activity in the university and, perhaps, in the country. We had some limitations but we knew we had to do it. We will look back to the experience as an occasion to serve the children of Myanmar".

\section{References}

1. Street Basketball Associaton. The Official Site of the Street Basketball Association. [Online] from http://www.streetbasketballassociation.net/about/history/ (n.d.). [Accessed on 22 March 2017].

2. Street Child United. Street child games. [Online] from http://www.streetchildunited.org/street-child-games-2016/5 (2016). [Accessed on 22 March 2017].

3. J. J. Coakley. Sport in society - issues \& controversies, 7th ed. Boston, MA: McGrawHill (2001). https://hope.rl.talis.com/items/5DEA1944-346D-60DC-4276682F1ABF8C92.html

4. V. Mumford, J. Kane. Journal of Physical Education, Recreation \& Dance, 77,3:3848(2006). https://www.tandfonline.com/doi/abs/10.1080/07303084.2006.10597843 
5. M. Miller, J. Nendel. Service-learning in physical education and other related profesions: A global perspective. Sudbury, MA: Jones \& Bartlett (2010).

https://www.amazon.com/Service-Learning-Physical-Education-Related-Professionsebook/dp/B007LA2JXS

6. K.A. Bush, M. Edwards, G.J. Jones, J.L. Hook. Service-learning in sports. [Online] from https://www.researchgate.net/publication/233524158_Service-

Learning in Sports (2016).

7. United Nation. Sports, development, peace, human rights, fitness, health. [Online] from http://www.un.org/en/events/sportday (2017).

8. G. Sankaran, K. Volkwein, D. Bonsal. HIV/AIDS in sport: Impact, issues and challenges. Ontario: Human Kinetics Publishers (1999).

https://www.amazon.com/HIV-AIDS-Sport-Impact-Challenges/dp/0880117494

9. E.N. Maleka. SAHARA-J: Journal of Social Aspects of HIV/AIDS, 14,1:1-21(2017). https://www.tandfonline.com/doi/full/10.1080/17290376.2016.1266506

10. M.R. Garcia, Social Action through Sports in Myanmar University, The LEAD (2016).

11. World Health Organization. Number of deaths due to HIV/AIDS. [Online] from http://www.who.int/gho/hiv/epidemic_status/deaths text/en/ (2016). [Accessed on 22 March 2017].

12. UNAIDS. Asian football community unites to Protect the Goal. [Online] from http://www.unaids.org/en/resources/presscentre/featurestories/2014/may/20140515ptg (2014). [Accessed on 22 March 2017].

13. UNAIDS. Country Fact sheet Myanmar. [Online] from http://www.unaids.org/en/regionscountries/countries/myanmar (2016). [Accessed on 22 March 2017].

14. University of New South Wales. Interview Dr Tun Aung Shwe from University of New South Wales [Online] from https://www.sbs.com.au/yourlanguage/burmese/en/audiotrack/interview-dr-tun-aungshwe-university-new-south-wales (2016). [Accessed on 22 March 2017]. 


\section{Documentation}

10.1 The Preparation - Training Participants

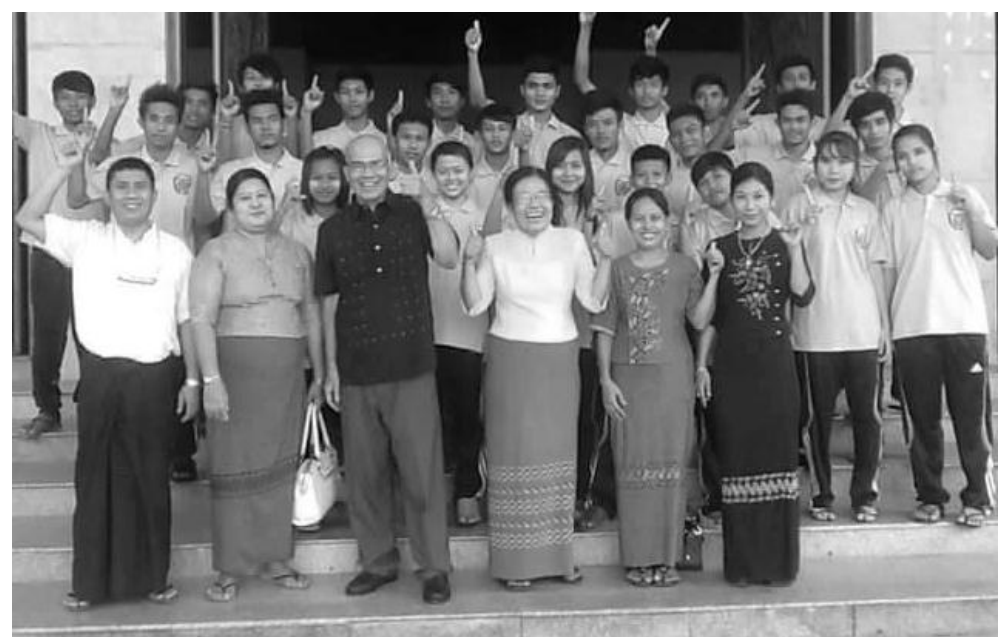

Students and mentors in the June training held in preparation for the S-L activity.



Dr. Tun Aung Shwer (UNSW Newsletter photo)

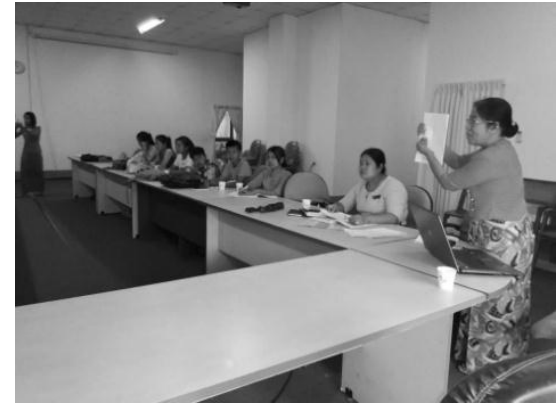

Coaching manual discussed 
10.2 The Sessions

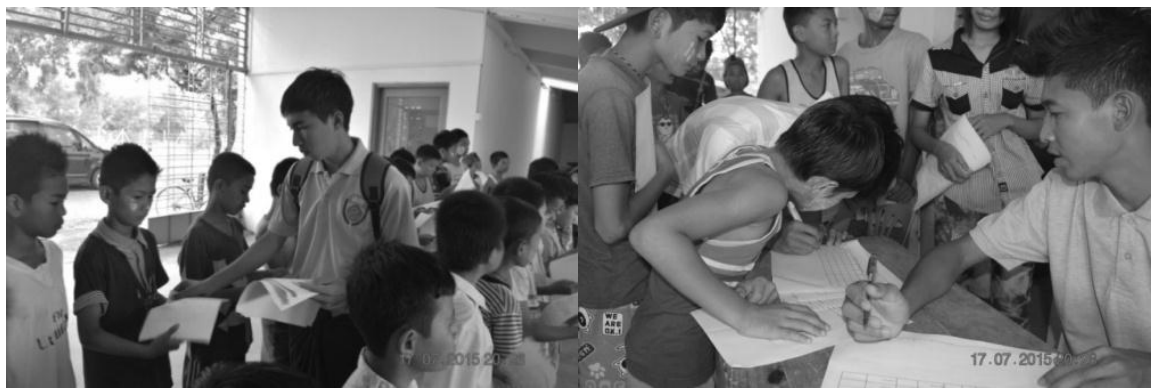

The sessions

\subsection{The Registration}

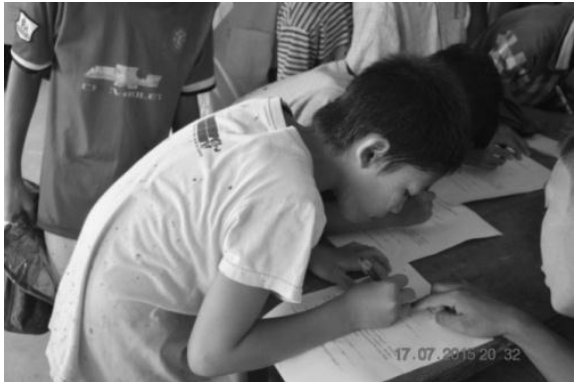

Pre-test session

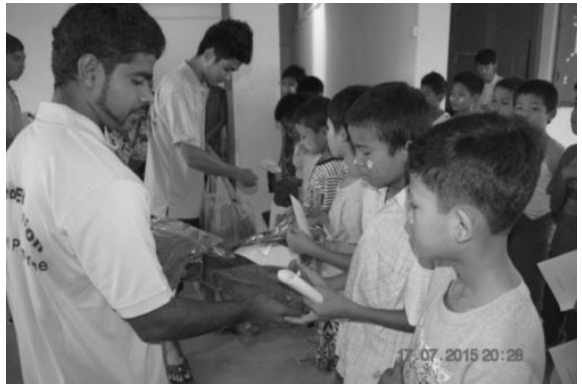

Uniform t-shirts for the children

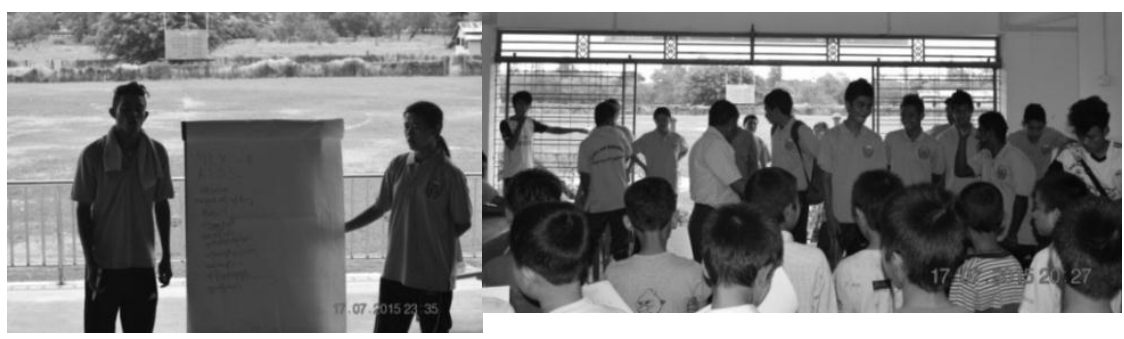

Lecture on HIV/AIDS

The service providers with service receivers



During the opening session 


\subsection{Skills Training}


Playing on a muddy field 


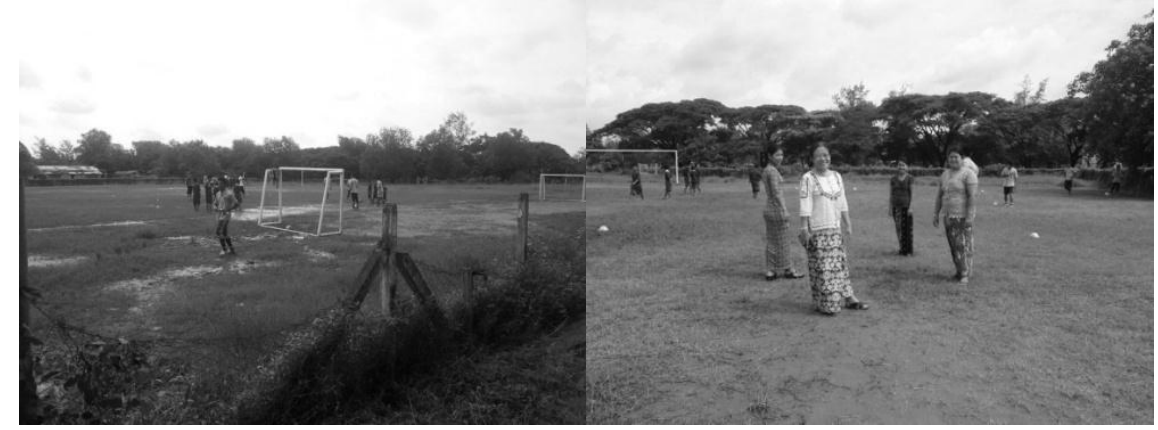

Mentors on field

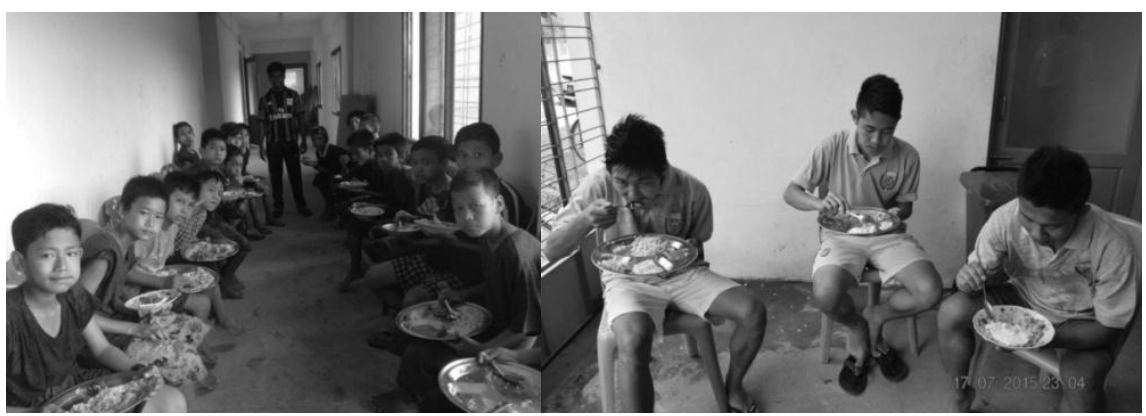

Meals for the children and university students after a tiring activity

\subsection{Evaluation}

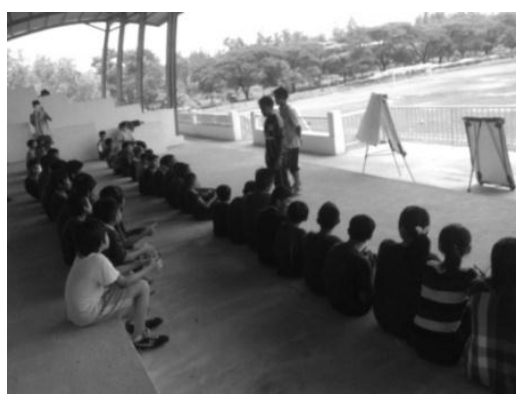

University students' evaluation

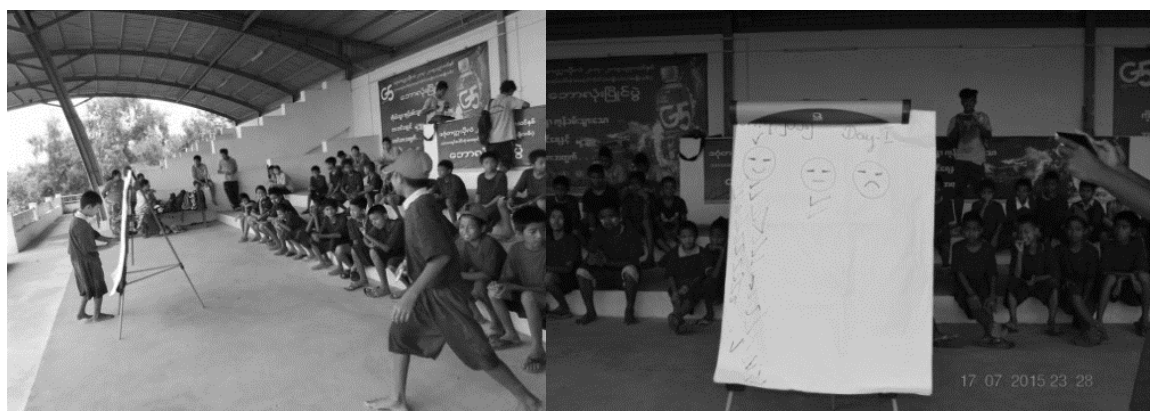

The Mood Meter evaluation for children 


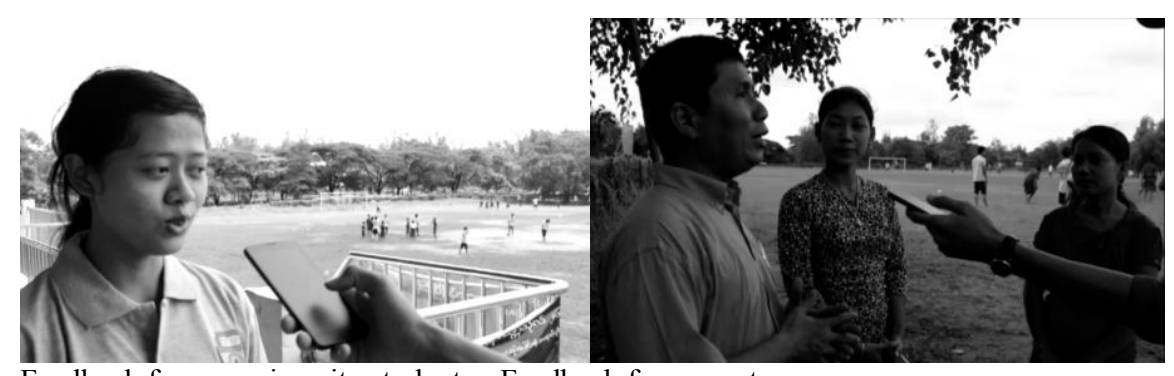

Feedback from a university student Feedback from mentors

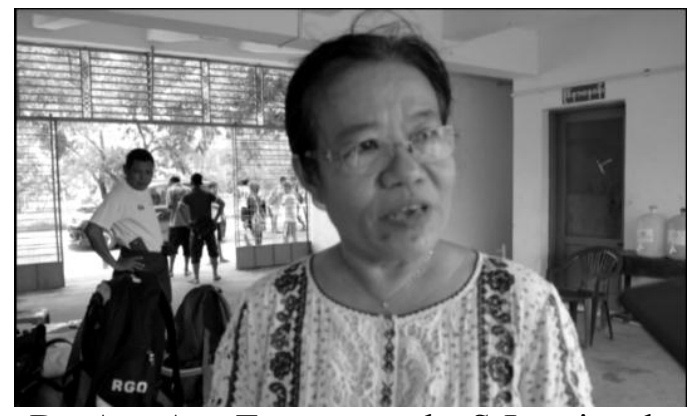

Dr. Aye Aye Tun recaps the S-L rationale

\subsection{The groups - S-L receivers and providers}
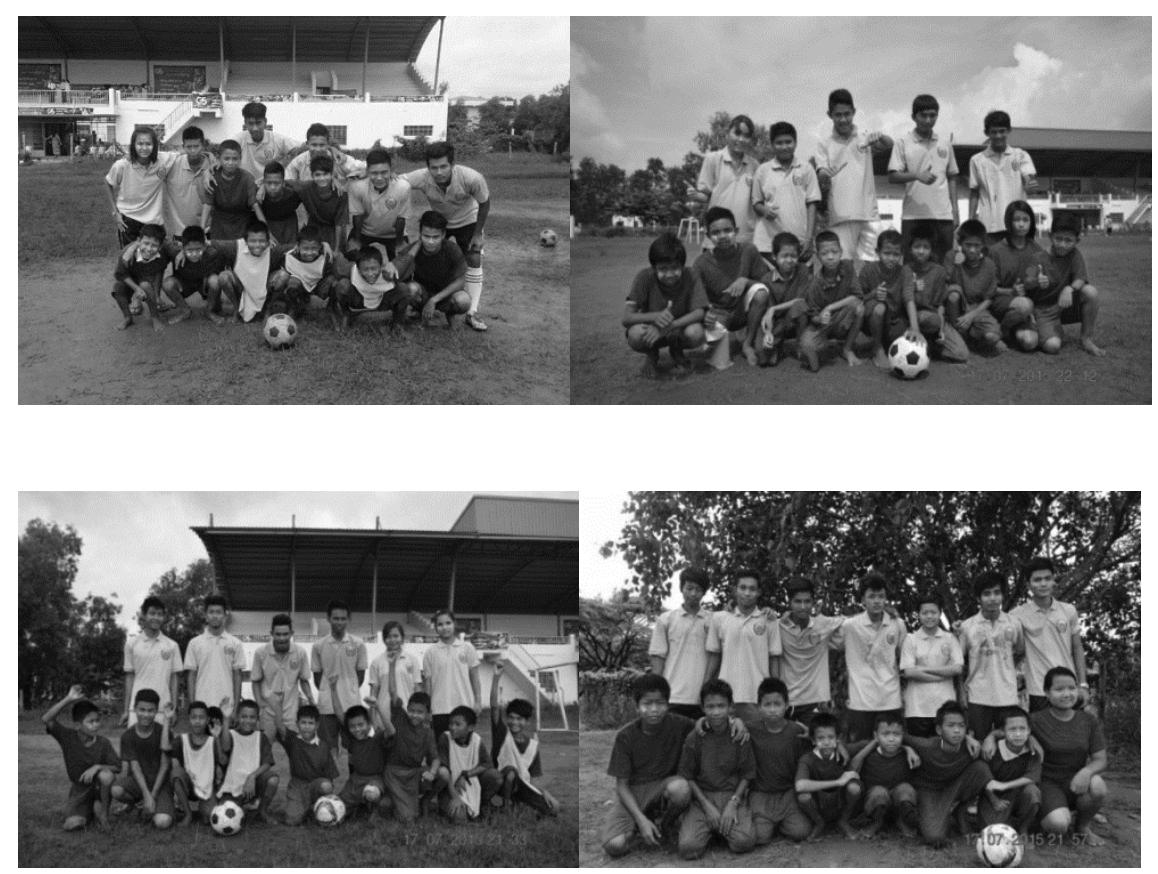




The university students and schoolchildren

10.6 Questionnaire: Evaluation of Knowledge on HIV-AIDS for the Schoolchildren

\begin{tabular}{|c|c|c|c|}
\hline \multicolumn{4}{|c|}{  } \\
\hline \multicolumn{4}{|c|}{ HIV } \\
\hline \multicolumn{4}{|c|}{ 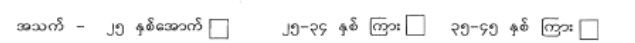 } \\
\hline & 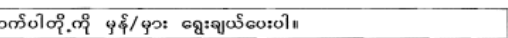 & १६̊ & ६९: \\
\hline 0 & 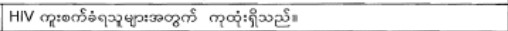 & & \\
\hline J & ஐईł⿱ & & \\
\hline s & 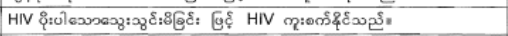 & & \\
\hline 9 & 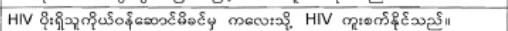 & & \\
\hline 2 & 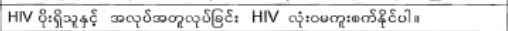 & & \\
\hline G &  & & \\
\hline$?$ & 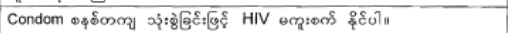 & & \\
\hline 。 & 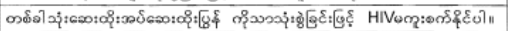 & & \\
\hline $\begin{array}{ll} \\
\end{array}$ & 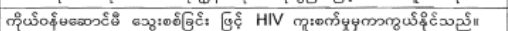 & & \\
\hline so & 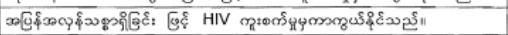 & & \\
\hline o & 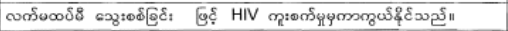 & & \\
\hline 01 & 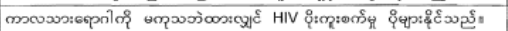 & & \\
\hline ग२ & 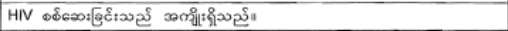 & & \\
\hline & 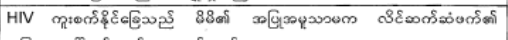 & & \\
\hline & 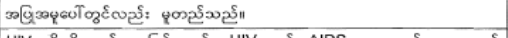 & & \\
\hline 9 & 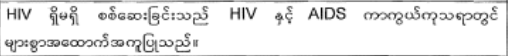 & & \\
\hline oG & 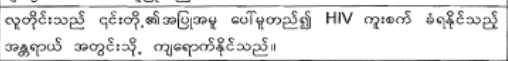 & & \\
\hline 20 & 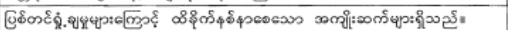 & & \\
\hline कo & 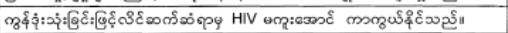 & & \\
\hline ग्ट & 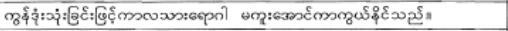 & & \\
\hline jo & 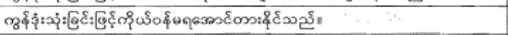 & & \\
\hline J2 & 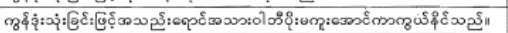 & & \\
\hline
\end{tabular}

